\title{
2015 european political science prize
}

doi:10.1057/s41304-016-0001-y; published online 6 June 2016

W

e are delighted to announce that the European Political Science Annual Prize for 2015 (Volume 14) has been awarded to Alexander Schmotz, King's College London, for the article "Vulnerability and compensation: constructing an index of co-optation in autocratic regimes" published in Volume 14, Issue 4 (2015), pp. 439-457.

This article develops an innovative index of co-optation in autocratic regimes, which goes beyond the usual limited institutional focus. The author argues that co-optation is constituted by the compensation of regime vulnerability through institutional inclusion and material benefits to various pressure groups. Consequently, the index is based on indicators of vulnerability and compensation for a variety of pressure groups from military, capital and labour to parties, ethnic groups and landowners.
Further, the index is tested on models of survival or breakdown of autocratic regimes. We find that this article makes an original contribution to the literature by offering a comprehensive measure of co-optation, and at the same time, the author is well aware of the limitations of the research, not least the scarcity of good indicators of compensation and vulnerability.

According to the statutes, this prize shall be given to an article that makes a substantial contribution to the field of political science. We are sure that Alexander Schmotz' article will be frequently cited in the future. It is innovative, theoretical sound, and - very impressive.

The 2015 prize committee consists of Profs.

Drude Dahlerup (Chair)

James Newell

Gianfranco Pasquino 